Voix et Images

volxetimages

\title{
Bibliographie de Normand Chaurette
}

\section{Nicolas Sarrasin}

Volume 25, numéro 3 (75), printemps 2000

\section{Normand Chaurette}

URI : https://id.erudit.org/iderudit/201501ar

DOI : https://doi.org/10.7202/201501ar

Aller au sommaire du numéro

\section{Éditeur(s)}

Université du Québec à Montréal

\section{ISSN}

0318-9201 (imprimé)

1705-933X (numérique)

Découvrir la revue

\section{Citer ce document}

Sarrasin, N. (2000). Bibliographie de Normand Chaurette. Voix et Images, 25(3), 510-522. https://doi.org/10.7202/201501ar d'utilisation que vous pouvez consulter en ligne.

https://apropos.erudit.org/fr/usagers/politique-dutilisation/ 


\title{
Bibliographie de Normand Chaurette
}

\author{
Nicolas Sarrasin, Université de Montréal
}

\section{CEUVRES}

\section{I.1. Théâtre}

Rêve d'une nuit d'hôpital, Montréal, Leméac, coll. "Théâtre", 1980, 106 p.

Provincetown Playbouse, juillet 1919, j'avais 19 ans, Montréal, Leméac, coll. "Théâtre ", 1981, $132 \mathrm{p}$.

Fêtes d'automne, Montréal, Leméac, coll. "Théâtre ", 1982, 138 p. Il existe une version antérieure sensiblement différente qui a pour titre Danielle Sarrera, dont le manuscrit existe toujours.

La société de Métis, Montréal, Leméac, coll. “Théâtre ", 1983, 143 p.

Fragments d'une lettre d'adieu lus par des géologues, Montréal, Leméac, coll. "Théâtre", $1986,105 \mathrm{p}$.

Les reines, Montréal/Arles, Leméac/Actes Sud, coll. "Papiers ", 1991, 94 p.

Je vous écris du Caire, Montréal, Leméac, coll. "Théâtre ", 1996, 81 p.

Le passage de l'Indiana, Montréal/Arles, Leméac/Actes Sud, coll. "Papiers ", 1996, 88 p.

"Stabat Mater I", Brèves d'ailleurs, Arles, Actes Sud, coll. "Papiers ", 1997, p. 21-32.

Petit Navire, Montréal/Arles, Leméac/Actes Sud, coll. "Papiers ", 1999, 56 p.

Stabat mater II, Montréal, Leméac/Actes Sud, coll. "Papiers ", 1999, 60 p.

États financiers, Montréal, Les Éditions du Silence, à paraître.

\section{I.2. Récits}

"La Chinoise", Cabiers de théâtre Jeu, no 32, 1984, p. 79-86.

Scènes d'enfants, Montréal, Leméac, coll. "Roman ", 1988, 150 p.

"La panne", Avoir 17 ans, Robert Lévesque (dir.), Montréal, Québec Amérique, coll. "Littérature d'Amérique", 1991, p. 37-52.

"Simplicité vaut mieux", XYZ. La revue de la nouvelle, $\mathrm{n}^{\circ} 28,1991$, p. 20.

"L'écolier disparu ", Les Cabiers de Prospéro, no 8, juillet 1996, p. 88-89. Repris dans La société de Normand Chaurette. Figures et manières (Jean-Michel Sivry, Montréal, Théâtre UBU, 1996, p. 78-79).

Le pont du Gard vu de nuit, suivi de Le poids des choses, Montréal, Leméac, coll. "Des bonheurs-du-jour ", 1998, $61 \mathrm{p}$. 


\section{3. Études, critiques}

"Lire/Écrire. Beauté baroque ", Versance, vol. I, n 1, avril 1979, p. 7-12.

"Les murs communicants", Cabiers de thêâtre Jeu, no 20, 1981, p. 132-136.

"Les risques du métier ", Les risques du métier, actes de la Rencontre internationale des écrivains tenue au Mont Gabriel du 27 avril au $1^{\text {er }}$ mai 1990, Montréal, l'Hexagone, 1991, p. 81-86.

"Interroger la place du texte au théâtre ", Chantal Hébert et Irène Perelli-Contos, Thêâtre, multidisciplinarité et multiculturalisme, Québec, Nuit blanche éditeur, 1997, p. 191-192.

\subsection{Traductions}

Othello, le More de Venise, traduction de Othello, the Moor of Venice de William Shakespeare, 1988.

Comme il vous plaira, traduction de As You Like It de William Shakespeare. Première version jamais jouée. Seconde version jouée à l'UQAM le 8 décembre 1990, repris à la Licorne le 21 février 1991 et à la Nouvelle Compagnie Théâtrale le 4 avril 1994.

Marie Stuart, traduction de Marie Stuart de Johann Christoph Friedrich von Schiller, en collaboration avec Marie-Élisabeth Morf (d'après sa traduction littérale): coproduction de la Nouvelle Compagnie Théâtrale et du Centre national des arts (Ottawa), 9 mars 1995.

Le songe d'une nuit d'été. Quelques chassés-croisés amoureux dans une Atbènes bucolique, traduction de A Midsummer Night's Dream de William Shakespeare: Théâtre du Trident, 3 octobre 1995.

Hedda Gabler, traduction de Hedda Gabler de Henrik Ibsen, d'après la traduction littérale de Sigrid Simonsen: Théâtre.du Nouveau Monde, 19 mars 1996.

La tempête, traduction de The Tempest de William Shakespeare: Théâtre du Trident, 28 avril 1998.

Coriolan, le sacrifié, traduction de The Tragedy of Coriolan de William Shakespeare, en collaboration avec Joël Jouanneau: Théâtre de l'Athénée-Louis-Jouvet (Paris), 29 septembre 1998.

Roméo et Juliette, d'après Romeo and Juliet de William Shakespeare: Théâtre du Nouveau Monde, 14 janvier 1999.

Les joyeuses commères de Windsor, traduction de The Merry Wives of Windsor de William Shakespeare, 1999.

Les dates correspondent à la première de la pièce.

\section{I.5. Inédits}

Danielle Sarrera, 1982. Version antérieure sensiblement différente de la pièce Fêtes d'automne.

Les conférencières, lecture publique à l'Institut culturel canadien durant le Carrefour international de théâtre, le 24 mai 1998 (étape finale d'un atelier d'un an d'écriture commandé par le Théâtre Ubu). 


\section{I.6. Préfaces}

"Monsieur Arsenault désarmé ou l'infernale comédie", préface de Panique à Longueuil de René-Daniel Dubois, Montréal, Leméac, coll. "Théâtre", 1980, p. 7-25.

"Les Trois Grâces ou une ode aux natures vivantes", préface aux Trois Grâces de Francine Ruel, Montréal, Leméac, coll, "Théâtre", 1982, p. vII-XxII.

"Le pouvoir et les mots ", préface de Ob! Gerry ob! de Jacqueline Barrette, Montréal, Leméac, coll. "Théâtre ", 1982, p. 7-18.

"Le jeune homme et la mort", préface de $26^{\text {bis }}$, impasse du Colonel-Foisy de RenéDaniel Dubois, Montréal, Leméac, coll. "Théâtre", 1983, p. vII-XXIV.

"Écrire le Songe, c'est le réinventer", préface au Songe d'une nuit d'été de William Shakespeare (traduction de Michelle Allen), Montréal, Leméac, coll. "Traduction et adaptation ", 1990, p. 7-10.

\subsection{Dramatiques à la radio}

Rêve d'une nuit d'bôpital, diffusée la semaine du 6 décembre 1976, voir Ici, RadioCanada/radio, $\mathrm{n}^{\circ} 239$, catégorie "Théâtre radiophonique" (version de la pièce différente de celle publiée).

L'âne de Bethléem, diffusée le 25 décembre 1989.

Extraits des Reines, de La société de Métis et de Provincetown Playbouse, juillet 1919, j'avais 19 ans diffusés le 2 novembre 1992 (Théâtre en clip à Radio-Canada FM).

Extraits des Reines et de Fragments d'une lettre d'adieu lus par des géologues diffusés le $1^{\mathrm{er}}$ mars 1993 (Théâtre en clip à Radio-Canada FM).

La Foresta, pièce à deux personnages (originalement écrite en 1982), diffusée à RadioCanada le $1^{\mathrm{er}}$ octobre 1993 et faisant partie des finalistes radio du prix Italia.

L'admirateur, 1993.

Nécrologie (adaptation d'une nouvelle de Dino Buzzati), 1993.

Magnificat, diffusée le 27 septembre 1994.

1994-1995: L'admirateur (énigmes en direct)

La mort d'Henry Wreck (énigmes en direct)

Entre Moscou et Saint-Petersbourg (énigmes en direct)

La Belle au bois dormant, texte inspiré du conte de Charles Perrault (énigmes en direct)

Le passage de l'Indiana, diffusée le 25 septembre 1995 (version sensiblement différente de celle qui a été publiée).

L'enfant prodigue, diffusée le 23 septembre 1996.

Provincetown Playbouse (Radiofiction en direct du Conservatoire d'art dramatique de Montréal, le 13 octobre 1997).

\subsection{Compte rendu}

"Scènes délogées de la folie: la troisième saison de l'Opéra de Montréal ", Cabiers de théâtre Jeu, no 28, 1983, p. 56-65. 


\section{PRIX ET DISTINCTIONS}

Premier prix du IVe Concours d'œuvres dramatiques de Radio-Canada, 1976, pour Rêve d'une nuit d'bôpital.

Prix Paul-Gilson (Communauté radiophonique des programmes de langue française, Lausanne), 1976, pour Rêve d'une nuit d'hôpital.

Prix de l'Association québécoise des critiques de théâtre (meilleur texte créé à la scène), 1988, pour Fragments d'une lettre d'adieu lus par des géologues.

Prix F. Lloyd Chalmers, 1993, pour The Queens (traduction des Reines par Linda Gaboriau).

Prix Dora Moore, 1993, pour The Queens (Toronto).

Prix du Gouverneur général, 1996, pour Le passage de l'Indiana.

Grand prix Tchicaya U Tam'si (Agence de la francophonie ACCT), 1996, pour Petit Navire.

Bourse d'écriture de l'Association Beaumarchais (Paris), 1996, pour Petit Navire.

Prix Beaumarchais SACD, 1996, pour Petit Navire.

Masque de la traduction, 1996, pour Songe d'une nuit d'été (William Shakespeare).

Prix CIC Paris Théâtre, 1997, pour Les reines.

Prix spécial de l'ACQT, 1997, pour le rayonnement à l'étranger.

Prix Essor du ministère de l'Éducation et de la Culture (France), 1997, pour Stabat Mater I.

Masque de l'Académie, 1998, pour Le passage de l'Indiana (catégorie texte original).

\section{RÉCEPTION CRITIQUE ET ÉTUDES}

\section{III.1. Articles, préfaces et chapitres de livres}

\section{III.1.1. Pièces de théâtre}

\section{III.1.1.1. Fêtes d'automne}

DUBOIS, René-Daniel, "Ils dansent sur la neige ", Fêtes d'automne, Montréal, Leméac, coll. "Théâtre ", 1982, p. IX-Xvil.

MOSS, Jane, "Trois grandes fêtes d'adieu ", Canadian Literature, Vancouver, no 98 , automne 1983 , p. $87-90$.

SCHULMAN, Samuel R., "Creative Works", French Review, vol. LVI, n 5, avril 1983, p. $785-786$.

\section{III.1.1.2. Fragments d'une lettre d'adieu lus par des géologues}

FORGUES, Michel, "Introduction", Fragments d'une lettre d'adieu lus par des géologues, Montréal, Leméac, coll. "Théâtre", 1986, p. 5-6.

NUTTING, Stéphanie, "L'écologie du tragique: Fragments d'une lettre d'adieu lus par des géologues de Normand Chaurette ", The French Review, vol. LXXI, $\mathrm{n}^{\circ}$ 6, mai 1998, p. 949-960.

RIENDEAU, Pascal, "Sens et science à la dérive dans Fragments d'une lettre d'adieu lus par des géologues", L'Annuaire théâtral, $\mathrm{n}^{\circ} 21$, printemps 1997, p. 84-101.

ROBERT, Lucie, "Les jeunes loups *, Voix et Images, vol. XII, n 3 (36), printemps 1987, p. 561-564. 
SERVIN, Micheline; "De Gorbatchev à la genèse, théâtre pour aujourd'hui ", Les Temps modernes, vol. XLVI, n 535 , février 1991, p. 171-189.

\section{III.1.1.3. Je vous écris du Caire}

O'NEILL-KARCH, Mariel, "Je vous écris du Caire", University of Toronto Quarterly, vol. LXVII, no 1, hiver 1997-1998, p. 394.

\section{III.1.1.4. Le passage de l'Indiana}

O'NEILL-KARCH, Mariel, "Le passage de l'Indiana", dans University of Toronto Quarterly, vol. LXVII, $\mathrm{n}^{\circ} 1$, hiver 1997-1998, p. 395.

\section{III.1.1.5. Provincetown Playhouse, juillet 1919, j'avais 19 ans}

CHAGNON, Gilles, "La scène cautérisée", Provincetown Playbouse, juillet 1919, j'avais 19 ans, Montréal, Leméac, coll. "Théâtre ", 1981, p. 9-18.

DAVID, Gilbert, "Dispositifs (post)modernes", L'Annuaire théâtral, $\mathrm{n}^{\circ} 21$, printemps 1997, p. 144-157.

GODIN, Jean Cléo, "Chaurette Playhouse ", Études françaises, vol. XXVI, n 2, automne 1990, p. 53-59.

GODIN, Jean Cléo, "Chaurette Playhouse", Jean Cléo Godin et Dominique Lafon, Dramaturgies québécoises des années quatre-vingt, Montréal, Leméac, 1999, p. 103-146.

GROSS, Robert F., "Offstage sounds: The permeable playhouse of Charles Charles", Theatre Research in Canada, vol. XVIII, n 1 , printemps 1997, p. 3-17.

HUFFMAN, Shawn, «Mettre la scène en cage: Provincetown Playbouse et Le syndrome de Cézanne", Theatre Research in Canada/Recherches théâtrales au Canada, vol. XVII, no 1, printemps 1996, p. 3-23.

LEFEBVRE, Paul, "Introduction", Robert Wallace (dir.), Québec Voices, Three Plays, Toronto, The Coach House Press, 1986, p. 9-16.

LOISELLE, André, "Paradigms of 1980's Quebecois and Canadian Drama: Normand Chaurette's Provincetown Playbouse, juillet 1919, j'avais 19 ans and Sharon Pollock's Blood Relations", Québec Studies, n 14, printemps-été 1992, p. 93-104.

MOSS, Jane, "From the asylum", Canadian Literature, n 96, printemps 1983, p. 143-145.

- " "Sexual Games: Hypertheatricality and Homosexuality in Recent Québec Plays ", American Review of Canadian Studies, vol. XVII, nº 3, 1988, p. 287-296.

TESSIER, Guy, "Surthéâtraliser dans le théâtre québécois", Frank Wilhelm (dir.), Le théâtre dans le théâtre, le cinéma au cinéma, Carnières, Lansman éditeur, 1998, p. $165-182$.

VILLENEUVE, Rodrigue, "One day my prince will come...", Protée, vol. XII, $n^{\circ} 2$, été 1984, p. 133-137.

\section{III.1.1.6. Les reines}

HINTON, Peter, "Foreword", The Queens, trad. de Linda Gaboriau, Toronto, The Coach House Press, 1992, p. 9-10.

LEFEBVRE, Paul, "Dans l'anarchie des ombrages", Les reines, Montréal/Arles, Leméac/Actes Sud, coll. "Papiers ", 1991, p. 5-6. 


\section{III.1.1.7. Rêve d'une nuit d'hôpital}

GODIN, Jean Cléo, "L'Angélus de l'instituteur", Rêve d'une nuit d'bôpital, Montréal, Leméac, coll. "Théâtre", 1980, p. 9-18.

WEISS, Jonathan M., "New Theatre in Quebec ", Canadian Literature, $\mathrm{n}^{\circ} 92$, printemps 1982, p. 143-146.

\section{III.1.1.8. La société de Métis}

GIRARD, Gilles, "La société de Métis", University of Toronto Quarterly, vol. LIII, $\mathrm{n}^{\circ} 4$, été 1984, p. 390.

MOSS, Jane, "Old Themes ", Canadian Literature, n 102, automne 1984, p. 100-101.

_-, "Normand Chaurette: La société de Métis", French Review, vol. LVIII, nº 6, mai 1985 , p. 915-916.

ROBILLARD, Monic, "Portrait de l'artiste", La société de Métis, Montréal, Leméac, coll. "Théâtre", 1983, p. 7-29.

\section{III.1.2. Récits}

\section{III.1.2.1. Scènes d'enfants}

ROY, Max, "Stratégies de lectures dans le roman contemporain ", Tangence, $\mathrm{n}^{\circ} 39$, mars 1993 , p. $76-88$.

\section{III.1.3 Autres}

DION, Robert, "Interprétation et processus judiciaire: Provincetown Playbouse, juillet 1919, j'avais 19 ans et Fragments d'une lettre d'adieu lus par des géologues", Le moment critique de la fiction, Québec, Nuit blanche éditeur, 1997, p. 89-111.

GODIN, Jean Cléo, "Deux dramaturges de l'avenir?", Études littéraires, vol. XVIII, n 3 , hiver 1985 , p. $113-122$.

- "Chaurette, critique et création ", La Licorne, Littérature de langue française en Amérique du Nord, 1993, n² 27, p. 187-193.

-, "Normand Chaurette, écriture et représentation", Théâtre/Public, n० 117, maijuin 1994, p. 52-53.

_ , "Le peintre invisible et la reine muette", Chantal Hébert et Irène Perelli-Contos (dir.), Théâtre, multidisciplinarité et multiculturalisme, Québec, Nuit blanche éditeur, 1997, p. 151-159.

GREFFARD, Madeleine et Jean-Guy SABOURIN, "Les voix nouvelles ", Le Théâtre québécois, Montréal, Boréal, 1997, p. 99-100.

HAMILL, Tony, Ann JENSEN, Marion GILSENAN et David FERRY (dir.), "You're Making a Scene, Scenes from Canadian Plays", Toronto, Playrights Canada Press, 1993, p. $272-278$.

LEFEBVRE, Paul, "Playwriting in Québec", Anton Wagner (dir.), Contemporary Canadian Theatre, Toronto, Éditions Simon \& Pierre, 1985, p. 67-68.

MOSS, Jane, "Still Crazy After All These Years. The Uses of Madness in Recent Québec Drama ", Canadian Literature, $\mathrm{n}^{\circ} 118$, automne 1988, p. 35-45.

RIENDEAU, Pascal et Bernard ANDRÈS, "La dramaturgie depuis 1980", Panorama de la littérature québécoise contemporaine, Réginald Hamel (dir.), Montréal, Guérin, 1997, chapitre IV, deuxième partie, p. 225-228. 
TEISSIER, Guy, "The 1980's", Joseph I. Donohoe Jr. et Jonathan M. Weiss (dir.), Essays on Modern Québec Theater, East Lansing, Michigan State University Press, 1995, p. 169-182.

\section{III.2. Thèses et mémoires}

CURA, Luis, Théâtralité et métathêâtralité dans le thêâtre québécois contemporain (1980-1990), mémoire de maîtrise, Montréal, Université de Montréal, 1991, p. 8193.

DAVID, Gilbert, Un théâtre à vif: écritures dramatiques et pratiques scéniques au Québec, de 1930 à 1990, thèse de doctorat, Montréal, Université de Montréal, 1995, $451 \mathrm{p}$.

DESTRAIT, Marie, De la création poétique à la spécificité théâtrale, analyse des deux premières pièces de Normand Chaurette, dramaturge québécois, mémoire de licence, Louvain, Université de Louvain, 1983, n.p.

GARCEAU, François, La problématique de la filiation dans le théâtre homosexuel québécois contemporain 1980-1990, mémoire de maîtrise, Montréal, Université de Montréal, 1998, 127 p.

LOFFREE, Carrie, L'ambiguité raisonnée de Provincetown Playhouse, juillet 1919, j'avais 19 ans de Normand Chaurette, mémoire de maîtrise, Sainte-Foy, Université Laval, 1994, $136 \mathrm{p}$.

RIENDEAU, Pascal, L'bybridité textuelle chez Normand Chaurette ou les manifestations d'une dramaturgie postmoderne, mémoire de maîtrise, Montréal, Université du Québec à Montréal, 1995, 142 p.

\section{III.3. Comptes rendus et articles de presse}

\section{III.3.1. Pièces de théâtre}

\section{III.3.1.1. Fêtes d'automne}

DESJARDINS, Normand, "Normand Chaurette. Fêtes d'automne", Nos livres, vol. XIII, $\mathrm{n}^{\circ} 412$, novembre 1982.

LARUE-LANGLOIS, Jacques, "Fêtes d'automne: aride, exigeant, fascinant", Le Devoir, 26 mars 1982, p. 17.

LAZAR, Hélène, "Fêtes d'automne (1982)", Livres et auteurs québécois, Québec, Presses de l'Université Laval, 1983, p. 159-160.

LÉPINE, Stéphane, "La passion selon Normand Chaurette", Cabiers de thêâtre Jeu, $\mathrm{n}^{\mathrm{O}} 24,1982$, p. $120-122$.

LÉVESQUE, Robert, "Normand Chaurette: dramaturge", Le Devoir, 20 mars 1982, p. 17.

NOËL, Louis-Michel, "Fêtes d'automne", Québec français, mai 1983, p. 9.

\section{III.3.1.2. Fragments d'une lettre d'adieu lus par des géologues}

BEAULIEU, Carole, "Les Québécois boudent les Africains", Le Devoir, 4 septembre 1987, p. 16.

BERTRAND, Nicole, "Normand Chaurette. Fragments d'une lettre d'adieu lus par des géologues , Nos livres, vol. XVIII, nº 7012, mai 1987.

BOURASSA, André G., "Deux pièces en forme d'interrogatoire ", Lettres québécoises, $\mathrm{n}^{\circ} 45$, printemps 1987 , p. 50-51. 
DAVID, Gilbert, "Michèle Magny plonge dans l'univers énigmatique de Normand Chaurette: Fragments d'une lettre d'adieu lus par des géologues au Théâtre d'Aujourd'hui, prise 2", Le Devoir, 14 octobre 1995; p. B-6.

LÉVESQUE, Robert, "Fragments d'une lettre d'adieu... Les voix de Normand Chaurette ", Le Devoir, 15 mars 1988, p. 13.

—, "En direct du Mékong", Le Devoir, 27 octobre 1995, p. B-9.

SALVAIL, Danielle, "Fragments d'une lettre d'adieu lus par des géologues", Cabiers de théâtre Jeu, $\mathrm{n}^{\circ}$ 47, 1988, p. 151-154.

—_, "Jeu a vu ", Cabiers de théâtre Jeu, n 78, mars 1996, p. 241-246.

\section{III.3.1.3. Je vous écris du Caire}

DAVID, Gilbert, "L'écriture théâtrale au contrepoint de l'opéra: Normand Chaurette crée Je vous écris du Caire au Théâtre d'Aujourd'hui ", Le Devoir, 23 octobre 1993, p. C-6.

LAZARIDÈS, Alexandre, "Je vous écris du Caire", Cabiers de théâtre Jeu, $\mathrm{n}^{\circ} 68$, septembre 1993, p. 181-184.

LÉVESQUE, Kathleen, "Un vaudeville ésotérique insupportable", Le Devoir, 28 octobre 1993, p. B-8.

\section{III.3.1.4. Le passage de l'Indiana}

BÉRARD, Sylvie, "Hiatus ", Lettres québécoises, n 87, automne 1997, p. 37-38.

CAYOUETTE, Pierre, "L'apprentissage du détachement ", Le Devoir, 2 novembre 1996, p. B-1.

COSTAZ, Gilles, "Festival d'Avignon: UBU et la presse française", Cabiers de théâtre Jeu, $\mathrm{n}^{\circ} 81$, décembre 1996, p. 68-70.

DAVID, Gilbert, "Les arcanes d'un auteur solitaire: Avec Le passage de l'Indiana, Normand Chaurette amorce une nouvelle phase de sa carrière de dramaturge ", Le Devoir, 21 septembre 1996, p. B-1.

GUAY, Hervé, "Le triomphe de l'intelligence „, Le Devoir, 11 novembre 1996, p. B-8.

HELLOT, Marie-Christiane, "Figures baroques", Cabiers de thêâtre Jeu, $\mathrm{n}^{\circ}$ 82, mars 1997, p. 42-46.

LÉPINE, Stéphane, "Dans les remous de l'Indiana", Cabiers de théâtre Jeu, $\mathrm{n}^{\circ} 78$, mars 1996, p. 96-103.

LÉVESQUE, Robert, "Le passage de l'Indiana", Parachute, $\mathrm{n}^{\circ} 85$, janvier-février-mars 1997 , p. 55-56.

LÉVESQUE, Solange et Hervé GUAY, "Les 20 jours ", Le Devoir, 7 décembre 1996, p. B-6.

L'HÉRAULT, Pierre, "Passages", Spirale, nº 153, mars-avril 1997, p. 23-24.

MILLOT, Pascale, "La conquête d'Avignon", L'Actualité, vol. XXI, $\mathrm{n}^{\circ} 17$, novembre 1996, p. 14-28.

RIOUX, Christian, "L'année du Québec à Avignon. Absent du festival depuis 1982, le Québec ne pouvait pas choisir meilleure année pour débarquer à Avignon ", $L e$ Devoir, 9 juillet 1996, p. A-1

- "Festival d'Avignon. Aux sources de la création; Normand Chaurette et Denis Marleau imposent un suspense sur les origines de l'Art ", Le Devoir, 11 juillet 1996, p. B-8. 


\section{III.3.1.5. Petit Navire}

BÉLAIR, Michel, "Le droit au mensonge ", Le Devoir, 20 mai 1997, p. B-10.

LÉVESQUE, Solange, "Voyage au bout de la vie", Le Devoir, 10 mai 1997, p. B-1.

MASSOUTRE, Guylaine, "Ce sont toujours les mêmes qui écopent", Cabiers de théâtre Jeu, $\mathrm{n}^{\circ} 84$, septembre 1997 , p. $18-19$.

\section{III.3.1.6. Provincetown Playhouse, juillet 1919, j'avais 19 ans}

BOURASSA, André G., "Une nouvelle écriture scénique: le théâtre en morceaux", Lettres québécoises, $n^{\circ} 42$, été 1986, p. 38-39.

COTNOIR, Diane, "Une photo ne vaut pas toujours mille mots", Cabiers de théâtre Jeu, $n^{\circ} 38,1986$, p. $104-105$.

DAVID, Gilbert, "À propos du désir ", Cabiers de théâtre Jeu, n 34, 1985, p. 140-142.

—, "Les territoires imaginaires de Chaurette. Reprise de Provincetown Playbouse, juillet 1919, j'avais 19 ans à l'Espace Go ", Le Devoir, 7 mars 1992, p. C-6.

DESJARDINS, Normand, "Normand Chaurette. Provincetown Playbouse, juillet 1919, j'avais 19 ans", Nos livres, vol. XIII, n 110, mars 1982.

DICKMAN, Marta, "Provincetown Playbouse, juillet 1919, j'avais 19 ans: Le triomphe de la beauté ", Cabiers de théâtre Jeu, $\mathrm{n}^{\circ}$ 64, septembre 1992, p. 126-130.

DIONNE, André, "Le théâtre qu'on joue ", Lettres québécoises, nº 28, hiver 1982-1983, p. 54-56.

JUBINVILLE, Yves, "Chercher l'espace unique", Spirale, n 116, été 1992, p. 17.

KRYSINSKI, Wladimir, "Vies et théâtres enchevêtrés ", Vice versa, n 38, juin-août 1992 , p. 40-41.

LAMARCHE, Linda, "Provincetown Playbouse, juillet 1919, j'avais 19 ans (1981)", Livres et auteurs québécois, Québec, Presses de l'Université Laval, 1982, p. 163-165.

LAPOINTE, Gilles, "Provincetown Playbouse, juillet 1919, j'avais 19 ans", Cabiers de théâtre Jeu, $\mathrm{n}^{\circ} 23,1982$, p. 156-157.

LEFEBVRE, Paul, "Une production remarquable présentée à Chicoutimi : Provincetown Playbouse, juillet 1919, j'avais 19 ans", Le Devoir, 17 novembre 1984, p. 30.

LÉVESQUE, Robert, "Provincetown Playbouse, juillet 1919, j'avais 19 ans. Une pièce fascinante, un spectacle quelconque ", Le Devoir, $1^{\mathrm{er}}$ octobre 1982, p. 11.

-, "Chaurette, auteur qui attend ", Le Devoir, 4 juin 1985, p. 1.

, "Entre six heures et sept heures ", Le Devoir, 14 mars 1992, p. C-7.

VILLENEUVE, Rodrigue, "Provincetown Playbouse, juillet 1919, j'avais 19 ans: À la lettre ", Cabiers de thêâtre Jeu, nº 64, septembre 1992, p. 123-125.

\section{III.3.1.7. Les reines}

CAYOUETTE, Pierre, "Les reines à la Comédie-Française", Le Devoir, 11 juin 1996, p. B-8.

CHAREST, Rémy, "Fin du monde sur la corde raide. Gill Champagne met en scène Les reines de Normand Chaurette ", Le Devoir, 18 octobre 1997, p. B-8.

—, "Les tourbillons de la couronne", Le Devoir, 30 octobre 1997, p. B-7.

DOLBEC, Michel, "Chaurette bien accueilli", Le Devoir, 30 mai 1997, p. B-11.

JUBiNVILLE, Yves, "L'auteur exilé", Spirale, no 105, avril 1991, p. 14. 
KRYSINSKI, Wladimir, "Les reines", Cabiers de thêâtre Jeu, $\mathrm{n}^{\circ}$ 60, septembre 1991 , p. 121-124.

LE ROUX, Monique, "Des reines de théâtre ", La Quinzaine littéraire, n 717, juin 1997, p. 25.

LÉVESQUE, Robert, “Des farces de reines", Le Devoir, 24 janvier 1991, p. B-3.

_ , "Normand Chaurette remporte le Chalmers pour The Queens", Le Devoir, 25 mai 1993, p. B-8.

MALBERT, Daniel, "Reines, dans les coulisses du pouvoir ", Le Français dans le monde, $\mathrm{n}^{\circ} 290$, juillet 1997, p. 18-19.

PONTAUT, Alain, "Les reines hallucinées, revues par Normand Chaurette", Le Devoir, 12 janvier 1991, p. B-8.

RIOUX, Christian, "Joué à la Comédie-Française ", Le Devoir, 7 mai 1997, p. B-7.

\section{III.3.1.8. Rêve d'une nuit d'hôpital}

BORDELEAU, Christian, "Nelligan blanc", Le Berdache, Montréal, $\mathrm{n}^{\circ} 23$, septembre 1981, p. 49.

BOURASSA, André G., "Quand les poètes deviennent personnages ", Lettres québécoises, $\mathrm{n}^{\circ} 26$, été 1982, p. 45-47.

DESJARDINS, Normand, "Rêve d'une nuit d'bôpital", Nos livres, vol. XI, novembre $1980, \mathrm{n}^{\circ} 329$.

LARUE-LANGLOIS, Jacques, "Rêve d'une nuit d'bôpital au Quat'sous ", Le Devoir, 15 janvier 1980, p. 17.

ROBERT, Lucie, "Rêve d'une nuit d'hôpital", Cabiers de théâtre Jeu, $\mathrm{n}^{\circ} 18,1^{\mathrm{er}}$ trimestre 1981, p. 124-125.

TÉTU DE LABSADE, Françoise, "Rêve d'une nuit d'bôpital (1980)", Livres et auteurs québécois, Québec, Presses de l'Université Laval, 1981, p. 151-153.

\section{III.3.1.9. La société de Métis}

DESJARDINS, Normand, "Normand Chaurette. La société de Métis", Nos livres, vol. XIV, $\mathrm{n}^{\circ}$ 5308, juillet-août 1983.

GODIN, Jean Cléo, "La sociêté de Métis", Cabiers de théâtre Jeu, n 46, 1988, p. 192194.

LAMONTAGNE, Gilles G., "Des odeurs de triomphe québécois ", Le Devoir, 14 octobre 1992, p. B-3.

LÉPINE, Stéphane, "Le théâtre qu'on joue", Lettres québécoises, n 48, hiver 1987-1988, p. 42-44.

LÉVESQUE, Robert, "Des estivants sans êté: La société de Métis au Théâtre d'Aujourd'hui ", Le Devoir, 29 septembre 1987, p. 13.

MIJJOURS, Diane, "La sociêté de Métis», Cabiers de théâtre Jeu, $\mathrm{n}^{\circ}$ 28, 1983, p. 148-149.

\section{III.3.1.10. Stabat Mater I}

GASCON, Annie, "Quand le thêâtre étudiant voyage: les Brèves d'ailleurs ", Lurelu, vol. XX, n 2, automne 1997, p. 51-54. 


\section{III.3.2. Récits}

\section{III.3.2.1. La Chinoise}

LEFEBVRE, Paul, "Chaurette et Dubois écrivent", Cabiers de théâtre Jeu, no 32, 1984, p. 75.

\section{III.3.2.2. Scènes d'enfants}

BOIVIN, Jean-Roch, "Ils écrivent au meurtre... ils écrivent et ils aiment ", Lettres québécoises, $\mathrm{n}^{\circ}$ 53, printemps 1989 , p. 24-26.

CHASSAY, Jean-François, "Faits divers", Spirale, no 85 , février 1989, p. 3.

DUBÉ, Yves, "L'assurance d'un été bienfaisant ", Le Devoir, 16 juin 1990, p. D-6.

ÉTHIER-BLAIS, Jean, "Croquis adultes pour piano", Le Devoir, 31 décembre 1988, p. C-9.

MARCOTTE, Hélène, "Scènes d'enfants de Normand Chaurette", Québec français, mai $1989, \mathrm{n}^{\circ} 74$, p. 22.

\section{III.3.3. Autres}

BOURASSA, André G., "Performance à Métis-sur-mer ", Lettres québécoises, $\mathrm{n}^{\circ} 32$, hiver 1983-1984, p. 39-40.

ROBERT, Lucie, "Minces propos", Voix et Images, vol. XXIII, n 1 (67), automne 1997, p. $181-188$.

\section{III.3.4 Sur les traductions de Normand Chaurette}

BAILLARGEON, Stéphane, “Reconstruire le casse-tête de Roméo et Juliette ", Le Devoir, 9 janvier 1999, p. B-3.

DAVID, Gilbert, "L'amour ou le jeu de séduction... comme il vous plaira. Alice Ronfard monte As You Like dans une traduction de Normand Chaurette, à la NCT ", Le Devoir, 9 avril 1994, p. C-7.

RIENDEAU, Pascal, "Normand Chaurette face à Shakespeare ou Traduisez Comme il vous plaira", L'Annuaire théâtral, $\mathrm{n}^{\circ}$ 24, automne 1997, p. 17-34.

\section{ENTRETIENS ET PORTRAITS}

\section{IV.1 Revues et journaux}

BEAUSOLEIL, Guy, "Normand Chaurette: d'un pari à l'autre", Thêâtre. Les cahiers de la maîtrise, $\mathrm{n}^{\circ} 1,1996$, p. 4-9.

CAYOUETTE, Pierre "C'est l'année Chaurette, en France et au Québec", Le Devoir, 9 novembre 1996, p. B-6.

DAVID, Gilbert, "Une dramaturgie à deux vitesses", Parachute, $\mathrm{n}^{\circ} 52$, octobrenovembre 1988 , p. 66-69.

ELIANI, Paul, "Normand Chaurette: "L'écriture est un acte de séduction" ", Nuit blanche, no 34 , décembre 1988-janvier-février 1989, p. 18-19.

GUAY, Hervé, "Normand Chaurette : l'éternel ado. Des récits avec d'étranges équations à plusieurs inconnues ", Le Devoir, 13 mars 1999, p. E-20.

JUBINVILLE, Yves, "Entretien avec Normand Chaurette", Spirale, $\mathrm{n}^{\circ} 151$, novembredécembre 1996, p. 7. 
LARUE-LANGLOIS, Jacques, "Normand Chaurette: un jeune dramaturge heureux", Le Devoir, 19 janvier 1980, p. 24.

LAZARIDÈS, Alexandre, Hélène BEAUCHAMP et Christine BORELLO, "Spectacles: critiques ", Cabiers de théâtre Jeu, $\mathrm{n}^{\circ}$ 57, décembre 1990, p. 152-159.

LEFEBVRE, Paul, "La magie de l'univers textuel de Chaurette", Virus Arts, Montréal, septembre 1982.

LÉVESQUE, Robert, "Un théâtre affranchi", Magazine littéraire, n 234, octobre 1986, p. $118-120$.

__, "Normand Chaurette aux lectures du T.I.L.F.", Le Devoir, 9 septembre 1987, p. 13.

—_, "La rentrée théâtrale: les trois coups avec Chaurette, Dubois, Laberge...", Le Devoir, 12 septembre 1987, p. C-1

___, "Normand Chaurette : le géologue du hasard ", Le Devoir, 28 août 1995, p. B-1.

LOFFREE, Carrie, "Normand Chaurette: pour mieux saisir l'insaisissablen, Nuit blanche, no 55, mars-avril-mai 1994, p. 59-62.

SADOWSKA-GUILLON, Irène, "Normand Chaurette, un art scientifique du langage ", Acteurs, ${ }^{\text {os }} 87-88$, janvier-février 1991, p. 79-80.

—_, "Normand Chaurette", Paris, tête d'affiche, $\mathrm{n}^{\circ}$ 18, février-mars 1991, p. 10-11.

—, "De Michel Garneau à Normand Chaurette: l'aventure québécoise de Gabriel Garran ", Cabiers de thêâtre Jeu, n 59 , juin 1991, p. 114-117.

\section{IV.2. Essais}

RIENDEAU, Pascal, La cobérence fautive. L'bybridité textuelle dans l'œuvre de Normand Chaurette, Québec, Nuit blanche éditeur, 1997, 164 p.

SIVRY, Jean-Michel (dir.), La sociêté de Normand Chaurette. Figures et manières, Montréal, Théâtre Ubu, 1996, 84 p.

\section{IV.3. Références}

DAVID, Gilbert, "Chaurette, Normand ", Corvin, Michel, Dictionnaire encyclopédique du thêâtre, Paris, Larousse, coll. "In Extenso ", 1998, p. 178.

ERMAN, Michel et Paul WYCZYNSKI, "Normand Chaurette", Anthologie critique. Littérature canadienne-française et québécoise, Laval, Éditions Beauchemin, 1992, p. 476-481.

GAUVIN, Lise et Laurent MAILHOT, "Normand Chaurette ", Antbologie des auteurs québécois, Montréal, Presses de l'Université de Montréal, 1987, p. 123-126.

GAUVIN, Lise et Gaston MIRON, "Normand Chaurette", Écrivains contemporains du Québec (anthologie), Montréal, l'Hexagone/Typo, 1997, p. 147-149.

GODIN, Jean Cléo, "Normand Chaurette", Eugene Benson et William Toye (dir.), The Oxford Companion to Canadian Theatre, Don Mills (Ont.), Oxford University Press, 1989, p. 90-91.

HAMEL, Reginald, John HARE et Paul WYCZYNSKI, "Normand Chaurette", Dictionnaire des auteurs de langue française en Amérique du Nord, Saint-Laurent, Fides, 1989, p. 292-293.

MCEWEN, Barbara, "Normand Chaurette", Eugene Benson (dir.), Oxford Companion to Canadian Literature, $2^{\mathrm{e}}$ éd., Toronto, Oxford University Press, 1997, p. 189-190. 
RIENDEAU, Pascal, "Fêtes d'automne", Aurélien Boivin (dir.), Dictionnaire des ceuvres littéraires du Québec (DOLQ), Saint-Laurent, Fides, à paraître (2000).

- _La société de Métis", Aurélien Boivin (dir.), Dictionnaire des œuvres littéraires du Québec (DOLQ), Saint-Laurent, Fides, à paraître (2000).

VILLENEUVE, Rodrigue, "Fragments d'une lettre d'adieu lus par des géologues", Harry Lane (dir.), Canada on Stage (1986-1988), Toronto, Professional Association of Canadian Theatres, 1991, p. 410.

—_, "Provincetown Playbouse, July 1919", Harry LANE (dir.), Canada on Stage (1986-1988), Toronto, Professional Association of Canadian Theatres, 1991, p. 262.

- _ , "La société de Métis", Harry Lane (dir.), Canada on Stage (1986-1988), Toronto, Professional Association of Canadian Theatres, 1991, p. 377.

-, "Provincetown Playbouse, juillet 1919, j'avais 19 ans", Gilles Dorion (dir.), Dictionnaire des ouvres littéraires du Québec, $t$. VI: 1976-1980, Saint-Laurent, Fides, 1994, p. 663-665.

—_, "Rêve d'une nuit d'bôpital", Gilles Dorion (dir.), Dictionnaire des auvres littéraires du Québec, t. VI: 1976-1980, Saint-Laurent, Fides, 1994, p. 690-691.

\section{Bibliographie}

Répertoire des membres du centre des auteurs dramatiques, dramaturgie québécoise et franco-canadienne, Montréal, Centre des auteurs dramatiques (CEAD), 1999, p. 26-27. 